\title{
Function Synergy of Cross-Linked Cationic PVA Polymer to AMPS-Type Fluid Loss Additive Used for Cement-Based Material
}

\author{
Hao Wang $\mathbb{D}^{1},{ }^{1}$ Ming Li $\mathbb{D},{ }^{1}$ Youzhi Zheng, ${ }^{2}$ and Tao $\mathbf{G u}^{2}$ \\ ${ }^{1}$ School of Materials Science and Engineering, Southwest Petroleum University, Chengdu 610500, China \\ ${ }^{2}$ Engineering Technology Research Institute, PetroChina Southwest Oil \& Gas Field Company, Guanghan, Sichuan 618300, China
}

Correspondence should be addressed to Ming Li; swpulm@126.com

Received 5 May 2019; Revised 25 August 2019; Accepted 7 November 2019; Published 14 March 2020

Academic Editor: Victor H. Perez

Copyright (c) 2020 Hao Wang et al. This is an open access article distributed under the Creative Commons Attribution License, which permits unrestricted use, distribution, and reproduction in any medium, provided the original work is properly cited.

In this research, a kind of 2-acrylamido-2-methylpropanesulfonic acid sodium salt- (AMPS-Na-) type copolymer additive, the fluid loss additive (FLA), named as FLA A additive, was used for research. The performance of FLA A was tested and found to fail in the effective control of free water and to hinder the hydration process for delaying the breaking of the early hydration shell. The reason for it was the absorbed behavior and chelating effect of the AMPS-Na unit to $\mathrm{Ca}^{2+}$ hydrating cement particles. Thus, a cationic polyvinyl alcohol (PVA) polymer, modified by glyoxal and boric acid, was discovered due to its excellence in associating with the FLA A additive for controlling the free cement-based material water amount and preventing the chelating effect of FLA A chains on the surface of the cement-based material. Glyoxal/boric acid-modified polyvinyl alcohol, abbreviated as PVAGB or PVA-G-B, was with special molecular properties, i.e., positive ZETA $(\zeta)$ potential characteristics and cross-linked molecular structure. Due to competitive absorbed behavior of glyoxal-modified hydroxyl groups and free $\mathrm{Ca}^{2+}$ released by the hydration product, the chelating effect of AMPS-Na units to $\mathrm{Ca}^{2+}$ was weakened and the possibility of FLA A chains being absorbed to the surface of the cement-based material was decreased. Then, the formation of a complete fluid loss system was obtained; i.e., the fluid loss volume decreased to less than $50 \mathrm{~mL}$ at $30^{\circ} \mathrm{C}$ and $108 \mathrm{~mL}$ at $80^{\circ} \mathrm{C}$ with 0.2 percentage by weight of cement (\%BWOC) of PVAGB and $0.50 \%$ BWOC (percentage by weight of cement) of FLA A. Besides, the hydration process of cement-based material was accelerated due to formation of more C-S-H gels in the early hydration period. As a result, the cement-based material not only showed no worse compressive-strength retrogression but also showed a stable 28-day compressive strength of $28 \mathrm{MPa}$.

\section{Introduction}

For more superior comprehensive performance of cementitious materials used in oil well cementing projects, different kinds of additives are being used for optimization of cementitious materials. Functionalization and higher effectiveness are the two essential factors when using these additives. In particular, polymeric additives were utilized. So, various molecular structure characteristics of these functional polymers, including types of special functional chemical groups, have created significant factors, which are exerting more and more important functions when designing new polymeric additives. For polymer additives used in cementitious materials with special functional side-chain units, such as 2-acrylamido-2-methylpropanesulfonic acid sodium salt
(AMPS), the optimization of these polymerizable units is necessary and effective for the excellent application function of polymer additive. And 2-acrylamido-2-methylpropanesulfonic acid sodium salt (AMPS) was a type of functional unit for polymeric additive, with which 2-acrylamido-2-methylpropanesulfonic acid sodium salt (AMPS-Na) could be formed by $\mathrm{pH}$ adjustment to sulfonic acid groups with sodium hydroxide. As a result, excellent properties, i.e., strong chelation ability $[1,2]$ and temperature/salt resistance [3] of relating polymer additives, could be obtained. However, when used in cement-based materials, functional failure occurred due to the physicochemical behavior of AMPS-Na units surrounding high positively charged metal ions.

AMPS-type fluid loss additive (FLA) was effective in the microstructure control of hydrating cementitious materials 
for chelating effect with high-valence hydrated ions, such as calcium ion $\left(\mathrm{Ca}^{2+}\right)$, and these positive ions were released by hydrating cementitious particles. Due to stronger and effective chelation effect of the AMPS-Na unit to calcium ion $\left(\mathrm{Ca}^{2+}\right)$ or other metal ion, chemisorption mechanism of the AMPS-type additive was a fact [4]. AMPS-Na showed stronger absorbed ability to $\mathrm{Ca}^{2+}$ hydrated cement particles when compared to AMPS, and AMPS-Na-type chains could be absorbed on the hydrating surface of cement-based materials; a better multilayer fluid loss control structure was formed due to the absorbed behavior of numerous polymer chains to the surrounding cement-based material. However, perfect function of the AMPS-Na-type additive was based on better dispersion of polymer chains and formation of filtration control multilayers, so as to reduce fluid loss volume of well cementing materials $[4,5]$, and most free water molecules across through every layer were blocked at certain parts of the cementitious materials [6].

Dias et al. [7], Han and Zhang [8], and Cui et al. [9] depicted that molecular structure characteristics of the polymeric fluid loss additive were the key points to improve fluid loss additive application effectiveness. Salami and Plank depicted that the highly dispersed grafting polymer structure was beneficial to overcome unnecessary side effects when contacting with electrolyte matters, such as metal ions [10]. Besides, Guo et al. indicated the control ability of the carboxylic group to retard side effects of the AMPS-type fluid loss additive and fluid loss control ability improvement [11]. With regard to chelation and absorption effects of AMPS$\mathrm{Na}$ to calcium ion, resistance of AMPS-type additives to calcium ion contamination reflected its fluid loss control ability and rheological properties of cement slurry, especially in high-temperature bore holes. And Liu et al. indicated that amphoteric polymers could be useful for anticalcium contamination [12]. Meanwhile, Salami and Plank depicted the influence of electrolytes to fluid loss additive, and their research results indicated that unsuitable cationic matters, such as $\mathrm{Mg}^{2+}$, were not beneficial for additive performance in oil well cement slurry [10].

So, as depicted by the above research results, for traditional AMPS-Na-type additives, which only showed physicochemical properties of the anionic polymer, the new components used for additive systems could become the key point to improve the effectiveness of the additive system.

In this research, a type of AMPS-type additive, the FLA A additive, was used to explore additive defects used for cement materials. During compression test, serious brittleness along the axial direction frequently occurred. This kind of brittleness could negatively affect exploitation operations after cementing, and on the other side, ductile fracture characteristics could be much more beneficial to cement mechanical performance when compared to brittle drawbacks [13-15]. Plank et al. depicted that PVA, as a kind of associated swellable colloidal polymer, showed no influence on the filter cake microstructure but significantly reduced filter cake permeability. And they showed no chemical absorbed behaviors to cement particles [16]. And for it to improve filtration control performance, as well as to weaken brittleness, chemically modified PVA polymer has been researched. So, a new type of cationic cross-linked polyvinyl alcohol, named as PVAGB, had been remarkably regarded, and it had been utilized for better fluid loss control ability and it was beneficial in accelerating the early hydration of cement-based materials [6], in which PVAGB possibly showed no chemically absorbed behaviors to cement particles, so as to keep the microstructure completion of cement itself and reduce its microstructure permeability.

In this research, the FLA A additive showed negative ZETA potential value and excellent chemisorption ability to calcium ions mostly due to numerous sulfonate groups $\left(\mathrm{SO}_{3}{ }^{-}\right)$on AMPS units. However, in experimental tests, fluid loss control abnormality and serious compression performance defects occurred. It was estimated that normal molecule distribution of FLA A was damaged due to long-chain molecule characteristics of the polymer additive, and fluid loss control ability was worse than expected.

Thus, doubts on the effectiveness of function of AMPStype additives were established. And further researches were carried out on FLA A additives. In experiments, FLA A additives showed obvious drawbacks even with $3 \%$ BWOC and excellent acetone-formaldehyde-type dispersants [5].

As Hussein et al. depicted, the mixture of different fluid loss additives at certain proportions could be beneficial to the formation of more excellent fluid loss control systems [17]. So, it was thought that the final aim of using fluid loss additives was to accelerate the formation of a complete fluid loss control system in cement slurry. For it, an estimated concept to a fluid loss-controlled microstructure of cementbased materials was established (Figure 1), and a spatially dispersed support to adjust FLA chain distribution formation was the possibility to constitute the system of completed fluid loss control multilayers. In research, polyvinyl alcohol (PVA), a commonly used adhesive, was often utilized for its better fluid loss control ability and benefits to hydration of cement-based materials [18]. And glyoxal was often used for PVA chemical group modification, i.e., polyvinyl acetal adhesive, which showed excellent adhesion performance to cement-based materials [19-21]. So, glyoxal-modified PVA could be used. Furthermore, a glyoxal-modified hydroxyl group was discovered to be with positive ZETA potential characteristics and it could possibly impose a chemisorption behavior on the FLA A additive when competing with $\mathrm{Ca}^{2+}$. Formation of chemisorption force between the sulfonate group on the FLA A chain and the glyoxal-modified hydroxyl group on the PVA chain was a possibility. In particular, a cross-linking technique was utilized to form a solid polymeric network dispersed in a material matrix. In previous research, cement-based materials showed an obvious retarding side effect when using cross-linked PVA polymers for filming effect $[6,8,16,22]$. However, the cross-linked network was stable with higher mechanical strength. So, a cross-linked cationic polyvinyl alcohol (PVA) polymer, modified by glyoxal $(G)$ and boric acid (B), could be used for better functional synergy of FLA A additives to form an excellent fluid loss control system. FLA A additives and this modified PVA (PVAGB) polymer were combined for improving the FLA A chain distribution state, and PVAGB was utilized as a microstructure additive of the FLA A 


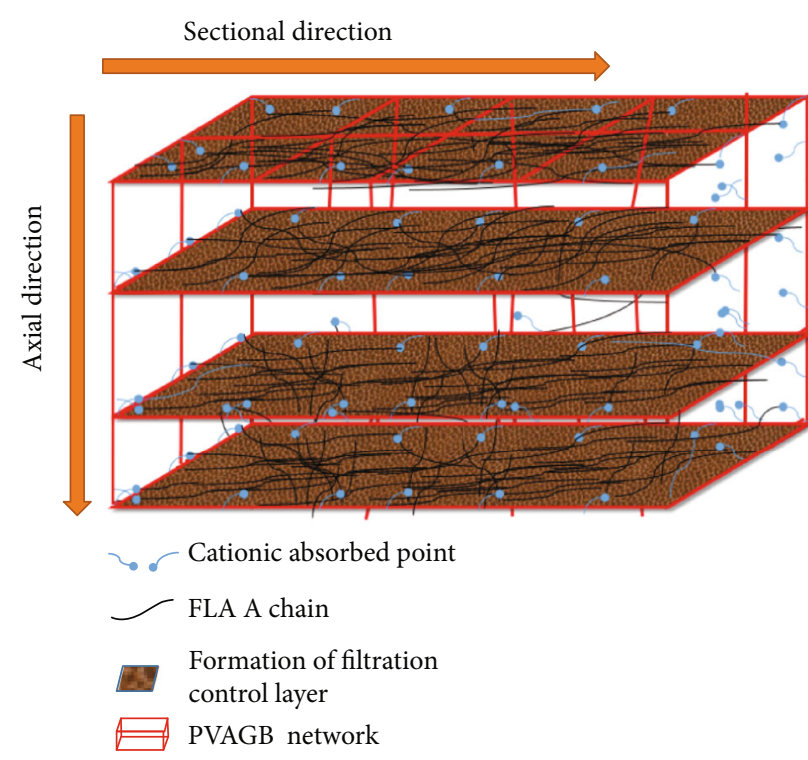

Figure 1: Schematic c. Note: the rearrangement of FLA A chain distribution was formed by absorption mechanism and the adjustment of the chain distribution by a spatially fixed and crosslinked network of the PVAGB polymer. Sectional direction was defined for the formation of filtration control multilayers. The direction was vertical to the flowing direction of cement slurry; free water was blocked on a certain layer to keep the perfect ratio of cement to water resulting in better hydration of cementitious material; axial direction was defined for the formation of filtration control multilayers. The direction was along the flowing direction of cement slurry. And free water possibly flowed along the axial direction micropore within the cement-based material, and the hydration process of the material was partly delayed or stopped due to lack of free water.

additive (Figure 1) rather than providing a stronger interface adhesion ability with larger addition for stronger binding force among cement particles $[23,24]$. This could be a possible solution to form chains in a uniform spatial distribution and could be formed by chemisorption mechanism of the FLA $A$ additive itself.

\section{Materials and Methods}

2.1. Materials. In research, the FLA A additive, an AMPStype fluid loss additive, which is a commercial product made in China, was used for research of absorption behaviors and mechanism of AMPS-type fluid loss additive used in cement-based materials. Furthermore, the PVA polymer, modified by glyoxal and boric acid, abbreviated as PVAGB (or PVA-G-B), which could be completely swelling-soluble in water (PVA, degree of polymerization, i.e., DP was 1788), was used for research on its physicochemical association effect on FLA A additives. Besides, formaldehydeacetone poly(condensate) was utilized as a dispersant for FLA A or PVAGB additives in the fluid loss system of cement-based materials [5], designated as SXY-2, which is a commercial product made in China. In addition, class $\mathrm{G}$ Portland cement, $\mathrm{Ca}^{2+}\left(\mathrm{CaCl}_{2}\right)$ agent, and $\mathrm{NaOH}$ agents, commercial products made in China, were also used.
2.1.1. Synthesis of PVA-Glyoxal-Boric Acid (PVAGB) Polymers. Synthesis of PVA-glyoxal-boric acid (PVAGB) polymers was done as mentioned above. Glyoxal was a better kind of adhesive modifier to reinforce adhesion performance of PVA-type additives, and these additives were beneficial to the cementing performance of inorganic materials, such as cement-based materials $[18,20]$. Besides, it may contribute to the well dispersion of cross-linked PVA in water for acetal chemical structures $[25,26]$. So, glyoxal $(G)$ and boric acid (B) were used as modification agents $[27,28]$. And the new modified PVA was designated as PVAGB polymer. Besides, to ensure a better hydrophilic property of the PVAGB polymer, urea (U) was utilized for keeping more residual hydroxyl groups [19]. Specifically, the synthesis procedure was the following: firstly, in a $500 \mathrm{~mL}$ reaction flask, $9 \mathrm{~g}$ of PVA was dissolved in $150 \mathrm{~g}$ of deionized water just under air atmosphere, and dissolution process was kept at $90 \sim 95^{\circ} \mathrm{C}$ for $1 \sim 2$ hours. The reaction flask was equipped with a reflux condenser, dropping funnel, and water bath kettle. To this solution, hydrochloric acid solution (50 wt.\%) was added to adjust the $\mathrm{pH}$ value of the PVA solution to $2 \sim 3$, and it was used as a reaction catalyst of aldolization reaction. Then, temperature of the PVA solution was adjusted to $80 \sim 85^{\circ} \mathrm{C}$. Secondly, with a dropping funnel, $3.6 \mathrm{~g}$ glyoxal (98\%, weight percentage) was dissolved in $89.4 \mathrm{~g}$ deionized water and added slowly for 0.5 hour. Then, the aldolization reaction was kept at $80 \sim 85^{\circ} \mathrm{C}$ for 2 hours. Then, the temperature was adjusted to $65 \sim 70^{\circ} \mathrm{C}$. Thirdly, the acetal reaction was stopped with sodium hydroxide $(\mathrm{NaOH})$ solution $(50 \mathrm{wt} . \%)$ and the $\mathrm{pH}$ value was adjusted to $7 \sim 8$. Finally, $0.06 \mathrm{~g}$ of boric acid was added to the solution and dissolved within $0.5 \mathrm{~h}$, then the cross-linking reaction was kept at $65 \sim 70^{\circ} \mathrm{C}$ for $1.5 \sim 2$ hours. So, glyoxal- and boric acid-modified PVA (PVAGB or PVA-G-B) polymer was formed. And the weight percentage of PVAGB was $5 \%$.

2.1.2. Preparation of Cement-Based Material Samples. As described, all referred additives and other materials were used for making the cement-based material according to the Chinese recommended standard of GB/T 19139-2012 [29] and API RP 10B-2 [30]; cement was mixed with different BWOC percentages of various polymer additives but with a fixed weight ratio, water to cement was 0.44 ; i.e., cement weight and water weight were, respectively, $800 \mathrm{~g}$ and $352 \mathrm{~g}$, with weight deviation of $0.1 \mathrm{wt} . \%$, and mixing speed was set at $4000 \mathrm{r} / \mathrm{min} \pm 250 \mathrm{r} / \mathrm{min}$ for 15 seconds to add cement or cement/dry additive blend to the water and then increased to a mixing speed at $12000 \mathrm{r} / \mathrm{min} \pm 250 \mathrm{r} / \mathrm{min}$ for $35 \mathrm{~s} \pm 1 \mathrm{~s}$. Then, for cementing of the material, all cement slurry was, respectively, poured into a sample mould for mechanical strength testing. The curing temperature for compressivestrength test was $60^{\circ} \mathrm{C}$, and the cement slurry mixture could be cured with 1 day, 3 days, 7 days, 14 days, and 28 days of curing time. It was maintained in an atmospheric-pressure water curing bath within $\pm 2^{\circ} \mathrm{C}$. The test was with four specimens of a set, and each strength value was obtained by average value of four tested values. Then, the curing temperature for sample preparation of scanning electron microscope (SEM) analysis was $60^{\circ} \mathrm{C}$, curing period 1 day, and then 
TABLe 1: XRF analysis of class G Portland cement chemical components.

\begin{tabular}{lccccccccc}
\hline Components & $\mathrm{Na}_{2} \mathrm{O}$ & $\mathrm{Al}_{2} \mathrm{O}_{3}$ & $\mathrm{MgO}$ & $\mathrm{SiO}_{2}$ & $\mathrm{CaO}$ & $\mathrm{K}_{2} \mathrm{O}$ & $\mathrm{Fe}_{2} \mathrm{O}_{3}$ & Loss & Others \\
\hline Weight percentage (\%) & 0.23 & 3.37 & 1.95 & 20.38 & 61.79 & 0.45 & 4.15 & 2.61 & 5.07 \\
\hline
\end{tabular}

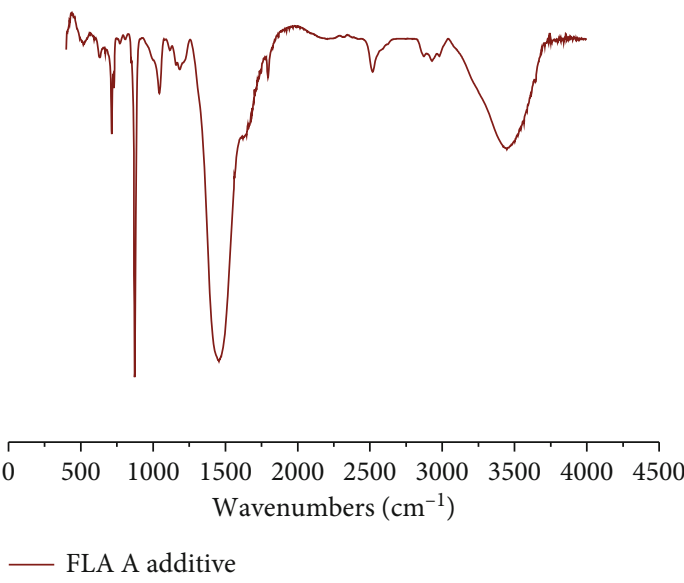

(a)
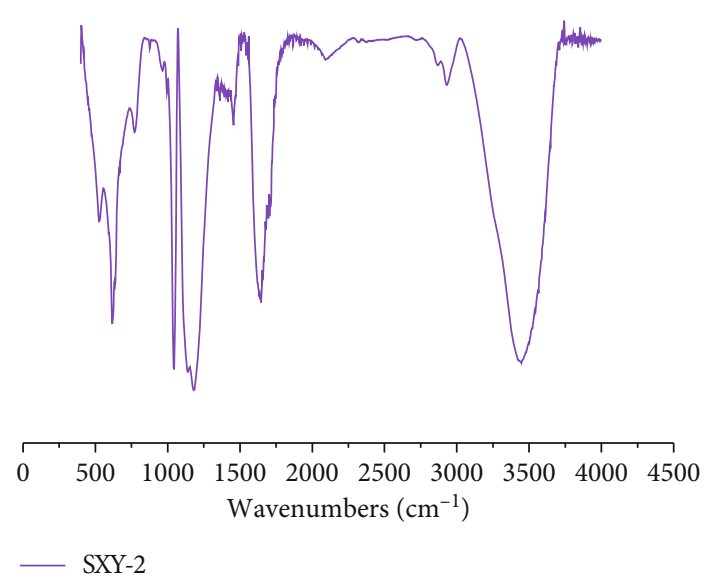

(b)

FIGURE 2: FTIR analysis of FLA A additive and SXY-2 dispersant.

freeze-drying operation in a vacuum drying oven for more than 48 hours.

\subsection{Characterization}

2.2.1. Physical and Chemical Properties of Used Materials. Class G Portland cement was tested with X-ray fluorescence (XRF) analysis, shown in Table 1 (provided by the producer). Chemical structure analysis of FLA A and SXY-2 is shown in Figure 2.

For the FLA A additive, the absorption peak at $3446 \mathrm{~cm}^{-1}$ that corresponds to $-\mathrm{NH}_{2}$, the absorption peaks at $2929 \mathrm{~cm}^{-1}$ and $2873 \mathrm{~cm}^{-1}$ that correspond to $-\mathrm{CH}_{3}$, and the absorption peaks at $1181 \mathrm{~cm}^{-1}, 1043 \mathrm{~cm}^{-1}$, and $632 \mathrm{~cm}^{-1}$ that correspond to $-\mathrm{SO}_{3}{ }^{-}$[31] were clearly observed, which represented the AMPS-Na unit that existed on the FLA A polymer chain. Besides, the absorption peaks at $1455 \mathrm{~cm}^{-1}$ corresponded to $-\mathrm{CH}_{2}$. So, on FLA A, $-\mathrm{SO}_{3}{ }^{-}$was the main chelating part to $\mathrm{Ca}^{2+}$ or other high-valence-state metal ions within cementbased materials. For the SXY-2 dispersant, the absorption peak at $3446 \mathrm{~cm}^{-1}$ corresponded to $-\mathrm{OH}$, the absorption peak at $2931 \mathrm{~cm}^{-1}$ corresponded to $-\mathrm{C}-\mathrm{H}$, the absorption peak at $1647 \mathrm{~cm}^{-1}$ corresponded to $-\mathrm{C}=\mathrm{O}$, and the absorption peak at $1182 \mathrm{~cm}^{-1}, 1043 \mathrm{~cm}^{-1}$, and $617 \mathrm{~cm}^{-1}$ corresponded to $-\mathrm{SO}_{3}{ }^{-}$ [31], which showed that the dispersant was one type of acetone-formaldehyde-sulfonate-based dispersant [5].

2.2.2. Compressive-Strength Test. Cement slurry tests were conducted, operated based on API RP 10B-2. Oil well classG cement, FLA A polymer additive, PVAGB polymer, dispersant SXY-2, and water were applied. The mixture samples were all $50.8 \times 50.8 \times 50.8 \mathrm{~mm}^{3}$ and used for compressivestrength testing (Table 2, compressive-strength tester). All mixture samples were cured at $60^{\circ} \mathrm{C}$ and normal atmospheric pressure, with a designed curing time of 1-day, 3-day, 7-day,
TABLE 2: Testing and characterization instruments.

\begin{tabular}{lc}
\hline Instruments & Model number \\
\hline $\begin{array}{l}\text { Compressive-strength tester } \\
\text { High-temperature and } \\
\text { high-pressure (HTHP) } \\
\text { fluid loss tester }\end{array}$ & TYE 300B (China) \\
$\begin{array}{l}\text { Fourier transform infrared } \\
\text { (FTIR) spectrum }\end{array}$ & OWC-9510 (China) \\
Scanning electron microscope & Scientific company, America) \\
& ZEISS EV0 MA15 \\
ZETA potential tester & ZEISS company, Germany) \\
& Dynamics company, America) \\
\hline
\end{tabular}

14-day, and 28-day periods, and a curing period for one set of four tested specimens. Compressive-strength testing procedure was referred by GB/T 19139-2012 and the API Recommended Practice 10B for compressive-strength testing. The cured rectangular specimens $\left(50.8 \times 50.8 \times 50.8 \mathrm{~mm}^{3}\right)$ were used to measure compressive-strength testing at a crosshead speed of $400 \mathrm{~N} / \mathrm{s}$. For evaluation of compressive-strength performance of tested specimens, an average strength value of four specimens was adopted.

2.2.3. Fluid Loss Test. Fluid loss test was done to verify cement slurry filtration loss volume and confirm function failure behaviors of the FLA A polymer additive with a high-temperature-high-pressure (HTHP) fluid loss tester (Table 2). This test was performed based on API Recommended Practice 10B. Test conditions were required at $30^{\circ} \mathrm{C}$ and $80^{\circ} \mathrm{C}$, with $6.9 \mathrm{MPa}$ test pressure. Besides, for testing at a specific temperature, all cement slurry mixtures were kept in a normal atmospheric-pressure consistometer for 20 minutes, with $150 \mathrm{r} / \mathrm{min}$ stirring and $30^{\circ} \mathrm{C}$ or $80^{\circ} \mathrm{C}$ constant 

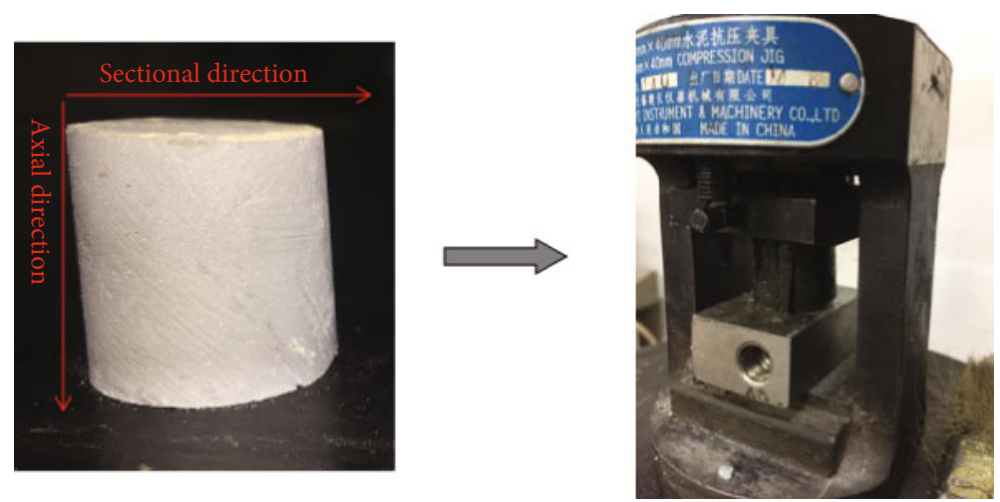

FIgURE 3: Illustration of spatial direction of cement-based material.

temperature heating operation, just as API 10B recommended. The test of every set of the additive formula was repeated at least twice except for the orthogonal analysis. If all results of every set were with a value deviation within $10 \sim 15 \mathrm{~mL}$, the results could be thought as regular and their average value could be the final result of this set, or it would be seen as a failure in the control of the fluid loss test. For confirming the failure of FLA A, the different contents of FLA A were adopted and the SXY-2 content was controlled to $0.2 \% \mathrm{BWOC}$ due to its possible negative result according to the relating compressive-strength test. For comparison, an orthogonal analysis at $30^{\circ} \mathrm{C}$ for the fluid loss test was carried out and for optimization of PVAGB content added with the FLA A additive. Then, further comparison was carried out at $80^{\circ} \mathrm{C}$ with different FLA A/PVAGB/SXY-2 content according to optimization results of the orthogonal analysis at $30^{\circ} \mathrm{C}$. Besides, $60^{\circ} \mathrm{C}$ was chosen as the test point for researching the physicochemical effect of FLA A additives and/or PVAGB additives to cement-based materials.

2.2.4. Microstructure Analysis. To confirm test results, especially a clear contrast in the fluid loss test and compression test before and after addition of PVAGB, SEM analysis was performed (Table 2, scanning electron microscope). For analysis of microstructure characteristics, cement-based material samples underwent curing in a $60^{\circ} \mathrm{C}$ atmospheric-pressure water curing bath within $\pm 2^{\circ} \mathrm{C}$ for 1 day, a freeze-drying operation of liquid nitrogen, and a more than 48-hour vacuum drying oven treatment. Then, the dried samples were compressed with the compressive-strength tester test (Figure 3) under certain strain stress forces $[32,33]$ along the sectional direction and axial direction of prepared samples (no touching operation was done), to obtain two types of hardened lamellar samples, which was along the sectional and axial directions of samples. Then, they were fully dried after more than $48 \mathrm{~h}$. During SEM analysis, all samples were made into an electrically conducting material and were deposited by a high vacuum evaporation operation.

2.2.5. FTIR Analysis of PVAGB Additive and Material Formulas with Different Additive Systems. For analysis of chemical structure characteristics of the PVAGB polymer, FTIR analysis was utilized for varieties of chemical groups before and after modification. The tested polymer product underwent drying operation of more than 48 hours and was then pulverized.

And FTIR analysis was utilized to test the chemical reaction and changes before and after additives were added into the cement-based material. And the tested samples were in the power state and made with pulverized cement-based material fragments of different additive formulae, which were cured in a $60^{\circ} \mathrm{C}$ atmospheric-pressure water curing bath within $\pm 2^{\circ} \mathrm{C}$ for 1 day. The tested cement-based material product underwent drying operation of more than 48 hours and was then pulverized.

2.2.6. ZETA Potential Test (Polymer Solutions). The FLA $A$ additive and/or PVAGB polymer was utilized to prepare a polymer aqueous solution, mass fraction no less than $1 \mathrm{wt}$. (solvent as deionized water). In particular, the FLA A/PVAGB mixture polymer additive solution mass ratio of FLA A to PVAGB was 5:2. Then, the $\mathrm{Ca}^{2+}$ additive $\left(\mathrm{CaCl}_{2}\right)$ of $0.6 \mathrm{~g} / \mathrm{L}$ may be added to FLA $\mathrm{A}$ and FLA $\mathrm{A} / \mathrm{PVAGB}$ polymer solutions to obtain an equivalent $\mathrm{Ca}^{2+}$ content in cement-based materials [34]. A NaOH agent was utilized to adjust the $\mathrm{pH}$ value to simulate the cement slurry chemical environment. The test condition was $30^{\circ} \mathrm{C}\left( \pm 2^{\circ} \mathrm{C}\right)$, with normal atmospheric pressure.

For simulation of the cement-based material formula, the weights of cement, deionized water, FLA A additive, PVAGB additive, and dispersant SXY-2 were, respectively, $800 \mathrm{~g}$, $352 \mathrm{~g}, 4 \mathrm{~g}, 1.6 \mathrm{~g}$, and $9.19 \mathrm{~g}$. Then, the hydrating product was with $0.6 \mathrm{~g} / \mathrm{L} \mathrm{Ca}^{2+}$. So, for simulation of the hydration environment but with no cement added, all other components were added in deionized water and an extra $\mathrm{Ca}^{2+}$ agent, $\mathrm{CaCl}_{2}$, of approximately $0.59 \mathrm{~g}$ was needed. The weight ratio was fixed, but the weight of used water was decreased.

Specifically, the preparation of polymer solutions was as follows:

Solution 1. FLA A (1.875 wt.) solution; 5.625 g FLA A polymer additive dissolved in $294.375 \mathrm{~g}$ deionized water

Solution 2. FLA A (1.875 wt.) solution and then $0.6 \mathrm{~g} / \mathrm{L} \mathrm{Ca}^{2+}$ added; $5.625 \mathrm{~g}$ FLA A polymer additive dissolved in $294.375 \mathrm{~g}$ deionized water. And $0.83 \mathrm{~g} \mathrm{CaCl}_{2}$ was added. The weight ratio of FLA A to $\mathrm{CaCl}_{2}$ was $4: 0.59$ 


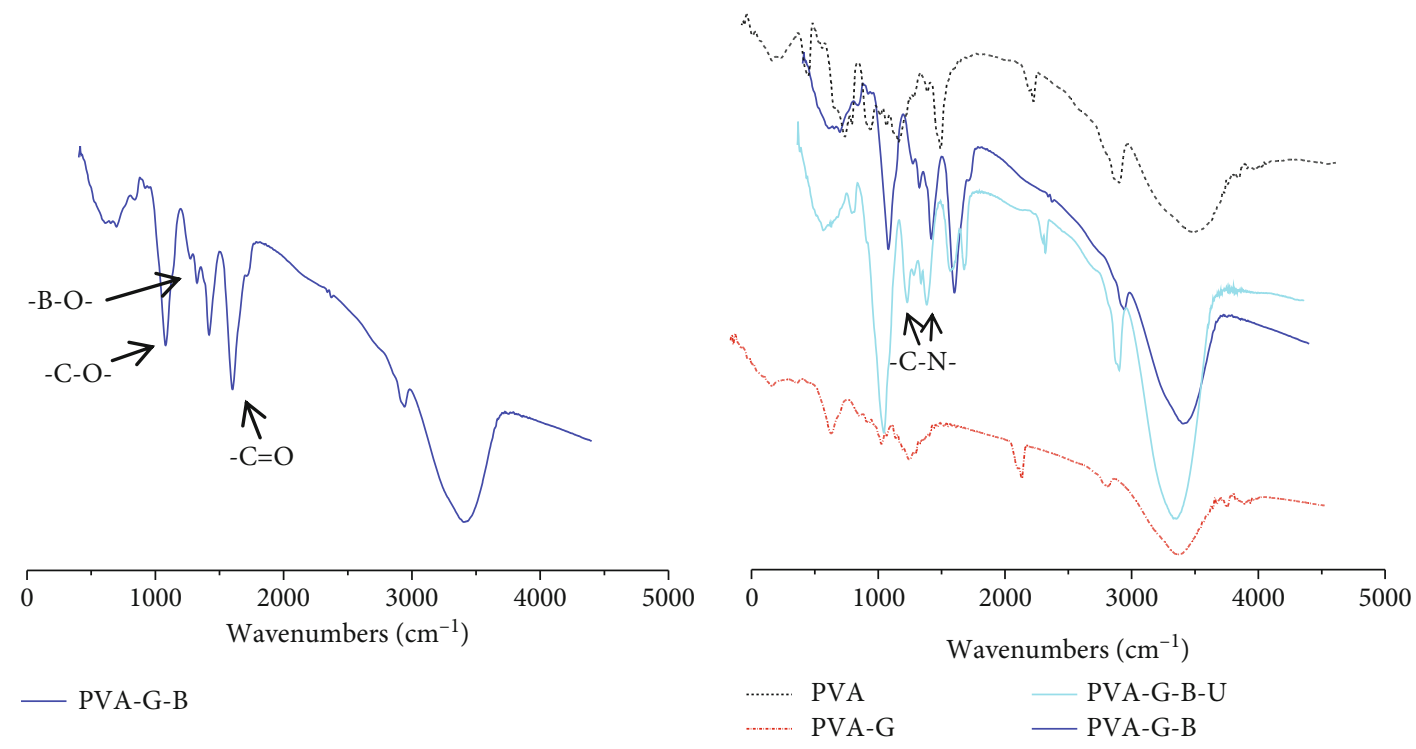

(a)

(b)

FIGURe 4: FTIR spectrum of the PVAGB polymer additive (solid blue line). PVA: polyvinyl alcohol; PVAGB-U: PVA modified by glyoxal, boric acid, and urea [19]; PVA-G: PVA modified by glyoxal; PVA-G-B: PVA modified by glyoxal and boric acid (also abbreviated as PVAGB).

Solution 3. Solution 2 was prepared and then $3.43 \mathrm{~g} \mathrm{NaOH}$ was added. Note: for the added $\mathrm{NaOH}, 3.5 \mathrm{~g} \mathrm{NaOH}$ added for $300 \mathrm{~g}$ deionized water, and $\mathrm{pH}$ values were tested with pH test strips. PVAGB (1.0 wt.) solution: $3 \mathrm{~g}$ FLA A polymer additive dissolved in $297 \mathrm{~g}$ deionized water (or $60 \mathrm{~g}$ of $5 \%$ PVAGB solution diluted with $240 \mathrm{~g}$ deionized water)

Solution 4. PVAGB (1.0 wt.) solution and then $0.6 \mathrm{~g} / \mathrm{L} \mathrm{Ca}^{2+}$ added; for $300 \mathrm{~g}$ of PVAGB (1.0 wt.) solution, $1.10 \mathrm{~g} \mathrm{CaCl}_{2}$ was added. The weight ratio of FLA A to $\mathrm{CaCl}_{2}$ was $1.6: 0.59$

Solution 5. Solution 4 was prepared and then $3.46 \mathrm{~g} \mathrm{NaOH}$ was added

Solution 6. Mixture of $200 \mathrm{~g}$ FLA A (1.875 wt.) solution and $150 \mathrm{~g}$ PVAGB (1.0 wt.) solution, i.e., $3.75 \mathrm{~g}$ FLA A additive and $1.5 \mathrm{~g}$ PVAGB additive were added in $294.75 \mathrm{~g}$ deionized water

Solution 7. $350 \mathrm{~g}$ of Solution 6 was prepared with $0.55 \mathrm{~g} \mathrm{CaCl}_{2}$ added. And then $4.02 \mathrm{~g} \mathrm{NaOH}$ was added. The weight ratio of FLA A to $\mathrm{CaCl}_{2}$ was $4: 0.59$, and the weight ratio of FLA A to $\mathrm{CaCl}_{2}$ was 1.6:0.59 (the weight ratio of FLA A to PVAGB was $4: 1.6$, i.e., $0.5: 0.2)$. Note: test condition is normal atmospheric pressure and normal temperature.

\section{Results and Discussions}

3.1. PVAGB Polymer Additive: FTIR Spectrum. As mentioned before, the modified PVA, the PVAGB (PVA-G-B) polymer, with urea (U) is taken as an indicator to maintain enough dispersed hydroxyl groups on PVA chains. As per the FTIR spectrum in Figure 4, it can be seen that there are two characteristic peaks at $1085 \mathrm{~cm}^{-1}$ and $1633 \mathrm{~cm}^{-1}$, indicating hydroxyl groups modified by glyoxal (G) agent, in which the peak at $1085 \mathrm{~cm}^{-1}$ represented the formation of a $-\mathrm{C}-\mathrm{O}$ heterocyclic ring and the peak at $1633 \mathrm{~cm}^{-1}$ represented $-\mathrm{C}=\mathrm{O}$ of an aldehyde group (-CHO) on modified PVA chains. The absorption peak of -B-O- was shown at $1324 \mathrm{~cm}^{-1}$, representing the modification effect of boric acid to hydroxyl groups. Furthermore, as shown in the PVAGB-U spectrum, the lower peak at $1290 \mathrm{~cm}^{-1}$ of the PVAGB spectrum has been covered by a nearby peak, and the dual peak of $\mathrm{C}=\mathrm{O}$ in the PVAGB-U spectrum, at $1600 \sim 1800 \mathrm{~cm}^{-1}$, resulted from the modification effect of glyoxal and urea. Urea (U) was used as indicators of residual hydroxyl groups, making all PVA chains the most dispersed hydroxyl groups retained according to the probability of reaction effect and adjacent-group effect [35], so as to eventually keep this PVA polymer additive with stronger hydrophilic performance. Moreover, a high hydrophilic performance could be a benefit to weaken the retarding side effect for the cross-linked PVA itself [16, 36].

Generally, glyoxal could be used as a cross-linker to chemical groups of $-\mathrm{OH}$ or $-\mathrm{NH}_{2}$; however, with the so-called acid kill, HCL added to adjust $\mathrm{pH}$ from $7 \sim 8$ to $2 \sim 4$, the crosslinking reaction was interrupted and chemical modification to -OH just happened [37]. For that, glyoxal-modified polyvinyl alcohol (PVA-G) could be obtained, and the product had the characteristics of positive ZETA potential matter. As a result, glyoxal-modified hydroxyl groups could possibly show positive ZETA potential characteristics and it could possibly impose the chemisorption behavior of FLA A additives to modified PVA polymer chains. Besides, in Liu et al.'s words, a new kind of amphoteric polymer, which could show better anticalcium contamination properties, was produced [12].

\subsection{Effect of FLA A Additive to Cement}

3.2.1. Fluid Loss Test. As shown in Table 3, for exploring the negative effect FLA A brought to cement-based materials, 
TABLe 3: Fluid loss test 1.

\begin{tabular}{lccccc}
\hline Test no. & $\begin{array}{c}\text { PVAGB } \\
(\% \text { BWOC })\end{array}$ & $\begin{array}{c}\text { FLA A } \\
(\% \text { BWOC })\end{array}$ & $\begin{array}{c}\text { SXY-2 } \\
(\% B W O C)\end{array}$ & \multicolumn{2}{c}{$\begin{array}{c}\text { Fluid loss }(\mathrm{mL}) \\
(30 \mathrm{~min})\end{array}$} \\
\hline $1 *$ & 0.20 & 0 & 0 & \multicolumn{2}{c}{452} \\
$2 *$ & 0.20 & 0 & 0.25 & \multicolumn{2}{c}{446} \\
$3 *$ & 0 & 1.0 & 0.25 & 195 & 235.2 \\
$4 *$ & 0 & 2.0 & 0.25 & 147 & 276 \\
$5 *$ & 0 & 3.0 & 0.25 & 67 & 91.9 \\
\hline
\end{tabular}

Note: test condition as $30^{\circ} \mathrm{C}, 6.9 \mathrm{MPa}$, and fluid loss in 30 minutes.

TABLE 4: Fluid loss test 2.

\begin{tabular}{lcccc}
\hline Test no. & $\begin{array}{c}\text { PVAGB } \\
(\% \text { BWOC })\end{array}$ & $\begin{array}{c}\text { FLA A } \\
(\% \text { BWOC) }\end{array}$ & $\begin{array}{c}\text { SXY-2 } \\
(\% B W O C)\end{array}$ & $\begin{array}{c}\text { Fluid loss }(\mathrm{mL}) \\
(30 \text { minutes })\end{array}$ \\
\hline 1 & 0.1 & 0.5 & 0.25 & 122 \\
2 & 0.1 & 0.75 & 0.50 & 46 \\
3 & 0.1 & 1.0 & 0.75 & 35 \\
4 & 0.15 & 0.5 & 0.50 & 58 \\
5 & 0.15 & 0.75 & 0.25 & 65 \\
6 & 0.15 & 1.0 & 0.75 & 33 \\
7 & 0.2 & 0.5 & 0.75 & 37 \\
8 & 0.2 & 0.75 & 0.25 & 33 \\
9 & 0.2 & 1.0 & 0.50 & 34 \\
K1 & 67.7 & 72.3 & 73.3 & $/$ \\
K2 & 52 & 48 & 46 & $/$ \\
K3 & 34.7 & 34 & 35 & $/$ \\
R & 33 & 38.3 & 38.3 & $/$ \\
\hline
\end{tabular}

Note: orthogonal test $\left(\mathrm{L}_{9}\left(3^{3}\right)\right)$. Test condition as $30^{\circ} \mathrm{C}, 6.9 \mathrm{MPa}$, and fluid loss in 30 minutes.

content of the SXY-2 dispersant was controlled to decrease to $0.25 \%$ BWOC and suitable for comparing with the FLA A/PVAGB/SXY-2 additive formula. Besides, addition of 0.2\%BWOC PVAGB showed no excellent fluid loss control ability. As a result of this test, fluid loss control ability of cement slurry could be mostly attributed to the addition of the FLA A additive. However, the fluid loss showed obvious difference for the same proportion of the FLA A additive, especially $2 \%$ BWOC. With the $2 \%$ BWOC FLA A additive, fluid loss in 30 minutes was shown as $147 \mathrm{~mL}$ and $276 \mathrm{~mL}$, which showed a $129 \mathrm{~mL}$ value deviation. And its utilization has caused a larger fluid loss volume than the use of $3 \%$ BWOC of FLA A. So, the FLA A additive showed an obvious defect in fluid loss control ability.

As per Table 4, contents of PVAGB, FLA A, and SXY-2 were the affecting factors and an orthogonal test was carried. Though PVAGB showed no excellent fluid loss control ability with the addition of $0.2 \sim 0.25 \%$ BWOC, an excellent fluid loss control coordinating effect with the FLA A additive was shown. According to Table 4, PVAGB showed excellent assistance to the FLA A additive even with $0.25 \% \mathrm{BWOC}$ SXY-2 added. The degree of effect of additives to fluid loss volume was as PVAGB $>$ FLA A $>S X Y-2$.
TABLe 5: Fluid loss test (comparison for SXY-2 added).

\begin{tabular}{lcccc}
\hline Test no. & $\begin{array}{c}\text { PVAGB } \\
(\% \text { BWOC) }\end{array}$ & $\begin{array}{c}\text { FLA A } \\
(\% \text { BWOC) }\end{array}$ & $\begin{array}{c}\text { SXY-2 } \\
(\% \text { BWOC })\end{array}$ & $\begin{array}{c}\text { Fluid loss }(\mathrm{mL}) \\
(30 \text { minutes })\end{array}$ \\
\hline 9 & 0.2 & 1.0 & 0.50 & 34 \\
$9^{\prime}$ & 0.2 & 1.0 & 0.75 & 30 \\
\hline
\end{tabular}

Note: test condition as $30^{\circ} \mathrm{C}, 6.9 \mathrm{MPa}$, and fluid loss in 30 minutes.

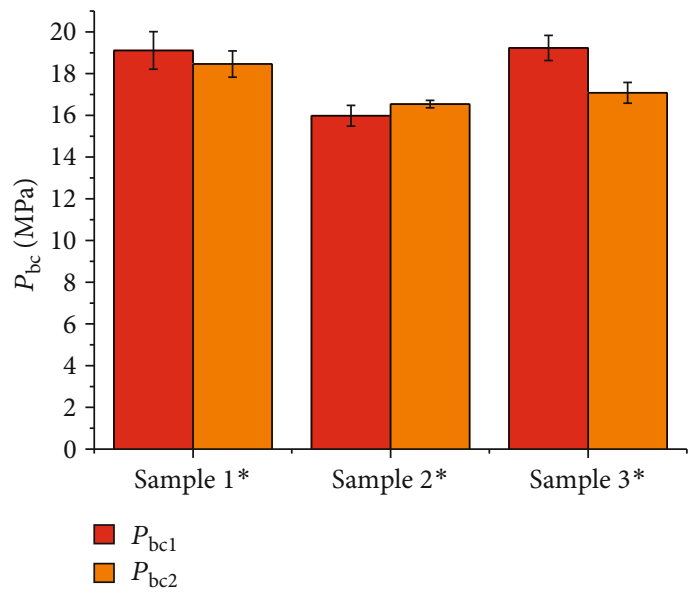

Figure 5: (1) Compressive-strength test 1. Columns in red color for samples containing only FLA A additive $\left(P_{\mathrm{bcl}}\right)$; columns in orange color for samples containing FLA A and $0.75 \%$ BWOC dispersant SXY-2 $\left(P_{\mathrm{bc} 2}\right)$. Sample $1 *: 1 \%$ BWOC FLA A; sample $2 *: 2 \%$ BWOC FLA A; sample $3 *$ : $3 \%$ BWOC FLA A. Note: $P_{\mathrm{bc} 1}$ and $P_{\mathrm{bc} 2}$ represent compressive strength of cement-based material samples.

As shown as Tables 4 and 5, due to the positive effects of higher content of SXY-2 added to the new additive formula (FLA A and PVAGB combined) ((9) compared with $\left(9^{\prime}\right)$ ), $0.75 \%$ BWOC showed better fluid loss control ability compared with $0.25 / 0.5 \%$ BWOC, so SXY-2 of $0.75 \%$ BWOC content could be utilized. And relatively higher content of PVAGB could be better for the fluid loss control ability when combined with FLA A; as (5) compared with (8), fluid loss volume was decreased from $65 \mathrm{~mL}$ to $33 \mathrm{~mL}$ (average value) when PVAGB content increased from $0.15 \%$ BWOC to $0.2 \%$ BWOC combined with $0.75 \%$ BWOC FLA A. Besides, due to the coordination effect of the PVAGB effect to FLA A with less content and comparison with FLA A, we selected $0.2 \% \mathrm{BWOC}$ PVAGB/0.5\%BWOC FLA A additive formula for further research, i.e., as the research background of SEM analysis and ZETA potential test.

3.2.2. Compressive-Strength Test. For exploring the effect of the FLA A and SXY-2 additive to cement-based materials, a control experiment was carried based on the 1-day compressive strength of cement-based materials. As shown as Figure 5(1), with 1-3\%BWOC, the tested compressivestrength value showed relative decrease compared to $0.7 \%$ BWOC added, even with the statistical similar value of sample $2 \#$ and sample $1 *$. For guaranteeing the effect of SXY-2, with/without SXY-2 operation was done and SXY-2 content was controlled as $0.75 / 0 \%$ BWOC. With dispersant addition, $2 \%$ BWOC addition showed relative 


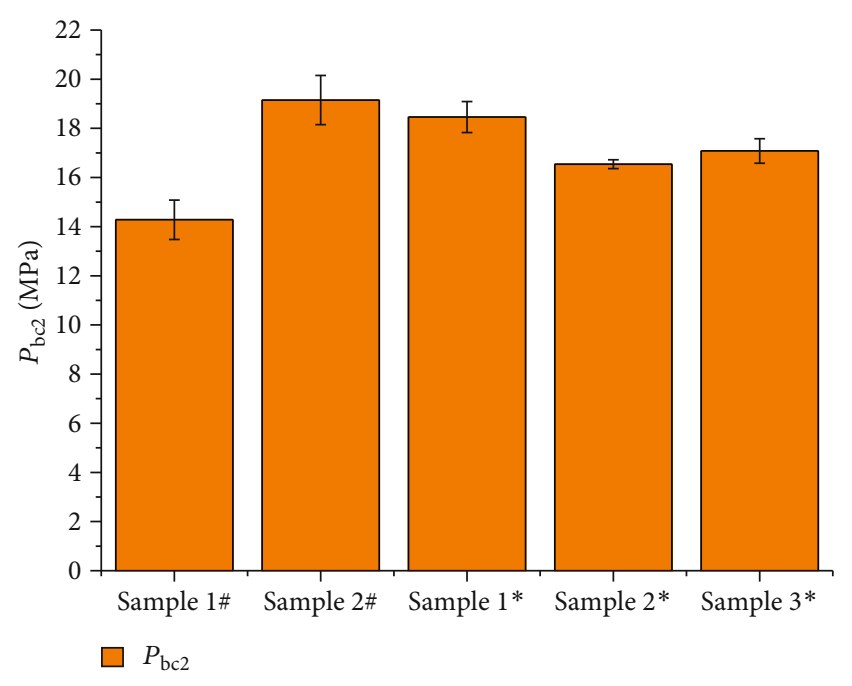

Figure 6: (2) Data contrast for compressive-strength test 1. Samples contain FLA A of different content and 0.75\%BWOC dispersant SXY-2. Sample 1\#: FLA A 0.5\%BWOC; sample 2\#: FLA A $0.7 \%$ BWOC; sample $1 *$ : FLA A $1 \%$ BWOC; sample $2 *$ : FLA A $2 \%$ BWOC; sample $3 *$ : FLA A $3 \%$ BWOC. All with $0.75 \%$ BWOC dispersant SXY-2. Note: $P_{\mathrm{bc} 1}$ and $P_{\mathrm{bc} 2}$ represent compressive strength of cement-based material samples.

decrease compared with a cement-based material sample with no SXY-2 added. Furthermore, shown in Figure 6(2), with one-day curing, when the FLA A additive content increased from $1 \% \mathrm{BWOC}$ to $3 \% \mathrm{BWOC}$, cement-based material samples showed a relatively weakening phenomenon in compressive-strength performance when compared to that of the $0.7 \%$ BWOC added. We found that a better FLA A content was approximately $0.7 \%$ BWOC. And failure of 1 3\%BWOC FLA A additive was shown in respect of mechanical performance. In this research, the filling effect of polymer adhesion was not the research key point $[38,39]$. And we could not conclude that the FLA A additive was not beneficial to the compressive strength. But, the addition of more FLA A additive did not contribute to a more stable compressive-strength development [38]. In the meantime, the SXY-2 dispersant, which was used for reinforce compatibility of the AMPS-type additive to other additives [40], showed no excellent positive effect to mechanical performance of cement-based material when the FLA A additive was added. So, the possible negative effect of $0.75 \%$ BWOC content of SXY-2 should be researched in a new FLA A/PVAGB additive system in respect of the compressive strength of cement-based materials according to the results of Figures 5(1) and 6(2). For research on the SXY-2 effect on cement-based materials, FTIR and SEM analyses were used.

3.2.3. Effect of Dual Use of PVAGB and FLA A to CementBased Material. There was no serious chemical side effect of PVAGB and FLA A addition by FTIR analysis, i.e., the distinction of varieties of covalent bonds in hydration products, with slight and regular intensity change. As shown in Figure 7, addition of PVAGB or FLA A and compound addition of these two types of additives could be chemically

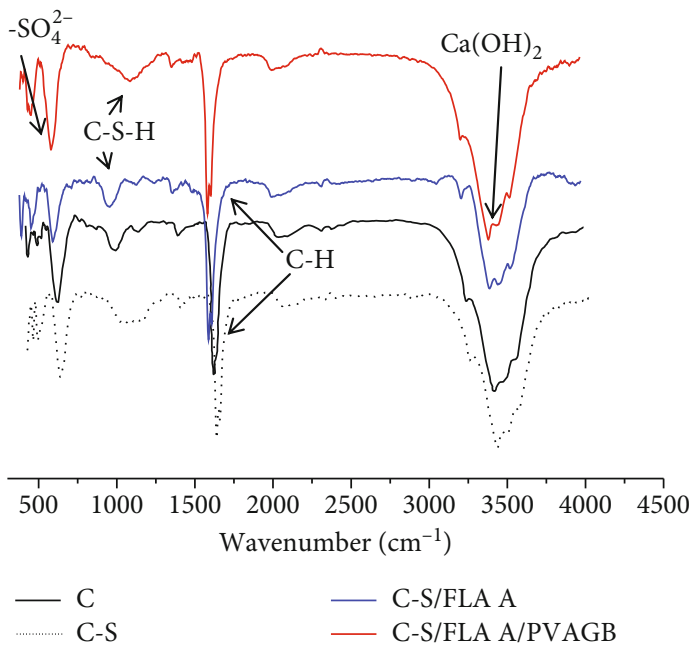

Figure 7: Effect of PVAGB and/or FLA A to cement-based material (FTIR). C: pure samples; C-S: samples with dispersant SXY-2; C-S/FLA A: samples with dispersant SXY-2 and additive FLA A; C-S/FLA A/PVAGB: samples with dispersant SXY-2 and additives FLA A and PVAGB.

safe to the material itself. Besides, what had been confirmed was the stronger absorbed behavior of the FLA A additive to cement particles due to its stronger chemical chelating effect of AMPS units to $\mathrm{Ca}^{2+}$ [4]. Although the absorption mechanism of the AMPS-type additive to $\mathrm{Ca}^{2+}$ has been proven to be a chemisorption mechanism [4], FLA A additives absorbed on $\mathrm{Ca}^{2+}$ hydrated cement particles resulted in no new chemical group products. In other words, no chemical reaction occurred between PVAGB and the FLA A polymer. However, firstly, when compared with a pure cement-based material, according to the absorption peak at $3400 \mathrm{~cm}^{-1}$ that represented $-\mathrm{OH}$ of $\mathrm{Ca}(\mathrm{OH})_{2}$ [41], SXY-2 showed a slightly accelerating effect to the hydration process compared to cement-based materials with no additive added. But its addition has no acceleration effect to the C-S-H gel formation according to the absorption peak at approximately $990 \mathrm{~cm}^{-1}$ that represented C-S-H gel [41-43]. And FLA A showed a negative effect to the hydration process according to a weaker absorption peak of $\mathrm{Ca}(\mathrm{OH})_{2}$ showing an absorption peak at about $3300 \mathrm{~cm}^{-1}[41,43]$, and the absorption peak at $617 \mathrm{~cm}^{-1}$ that represented sulfate ions $\left(-\mathrm{SO}_{4}{ }^{2-}\right)$ [41, 43]. Among the SXY-2, FLA A, and PVAGB additives, PVAGB showed an excellent positively improving effect to the hydration process when FLA A and the dispersant SXY2 were all added. For PVAGB addition, a stronger absorption peak for the C-S-H gel was shown. Due to the association effect of chains of the C-S-H gel, the absorption peak of the $\mathrm{C}-\mathrm{S}-\mathrm{H}$ gel was wider. So, FLA A hindered the hydration process of the cement-based material although addition of SXY2 partly accelerated the hydration process (compared with the pure cement-based material with no additive added). Besides, the absorption peak at $1617 \mathrm{~cm}^{-1}$ represented $\mathrm{C}-\mathrm{H}$ [43], but all tested samples had similar intensity.

3.2.4. SEM Analysis. As depicted in Figure 8, agglomerating behaviors of additive chains themselves were wrongly 


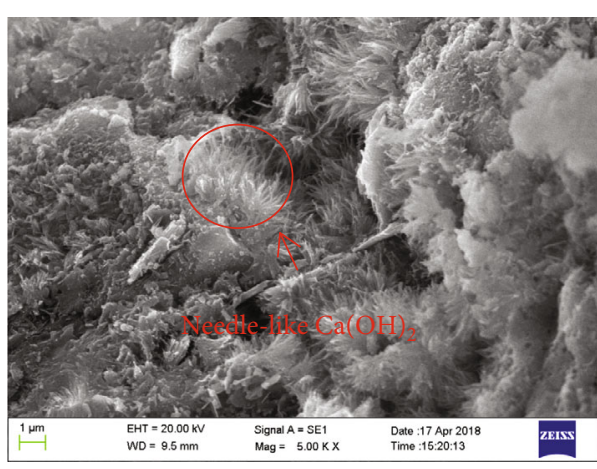

(a)

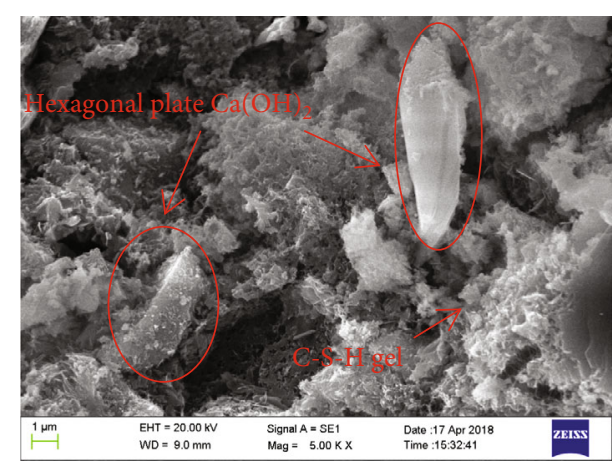

(b)

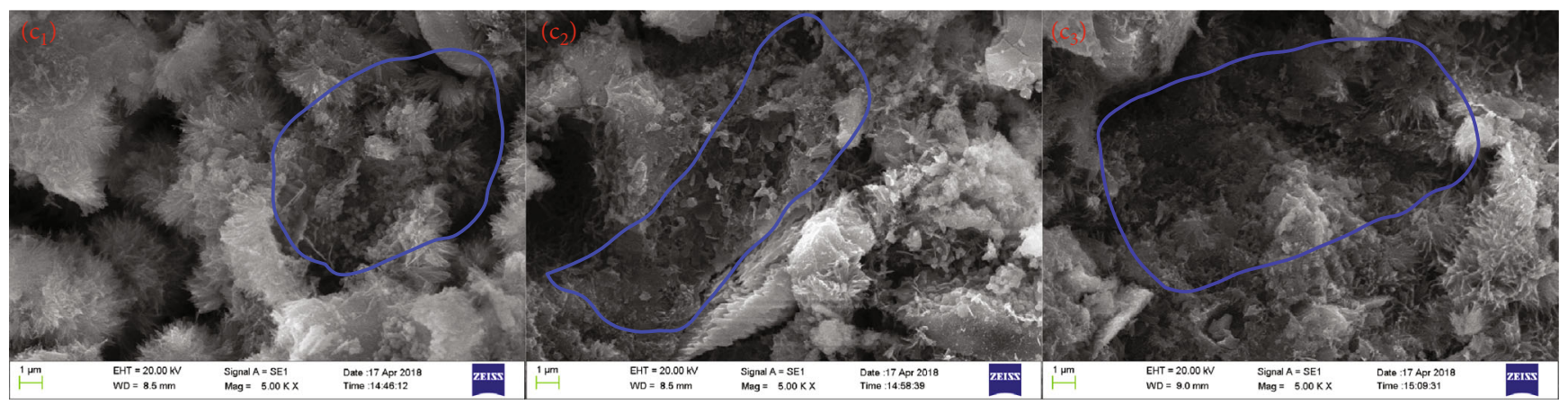

(c)

FIGURE 8: SEM images of different types of cement-based material samples (axial direction). (a) Pure samples; (b) pure samples with dispersant SXY-2 (0.75\%BWOC); (c) samples with dispersant SXY-2 (0.75\%BWOC) and additive FLA A ((c $\left.c_{1}\right)$ 1\%BWOC, (c c $\left._{2}\right)$ 2\%BWOC, and $\left(c_{3}\right) 3 \%$ BWOC).

absorbed to cement particles on some part interfaces of the cement-based material rather than being dispersed and uniformly distributed. According to SEM test results, the entanglement behavior of most absorbed polymer chains was mainly in a mess and entangled distribution along the axial direction of cement-based materials in spite of utilizing the better dispersing property of acetone-formaldehyde sulfonate dispersant. And thus, the incompatible and gluing interface was formed in the gap within cement-based materials in the early hydration period. The hydration shell formed in the early period could not break and free water leaked along the gluing interface rather than contacting with more cement particles, which was disadvantageous to the secondary hydration of the cement clinker. As an incompatible and gluing interface formed, the free water could not be kept as crystal water of hydrating products.

With addition of SXY-2, cement-based materials showed a phase transformation of the hydration product; the long needle-like portlandite $\left(\mathrm{Ca}(\mathrm{OH})_{2}\right)$ was transformed into a hexagonal plate form, which showed the phase completion phenomenon compared to partly radially growing formation of $\mathrm{Ca}(\mathrm{OH})_{2}$ [44]. And a certain part of the C$\mathrm{S}-\mathrm{H}$ gel aggregated product was formed. Though FLA A was added, a gluing phenomenon was observed, which caused the aggregation and gluing behaviors on these parts of interfaces, and was possibly due to AMPS-Na units absorbed on $\mathrm{Ca}^{2+}$ hydrated cement particles. Besides, no hexagonal plate $\mathrm{Ca}(\mathrm{OH})_{2}$ was formed when FLA A was added even with SXY-2.

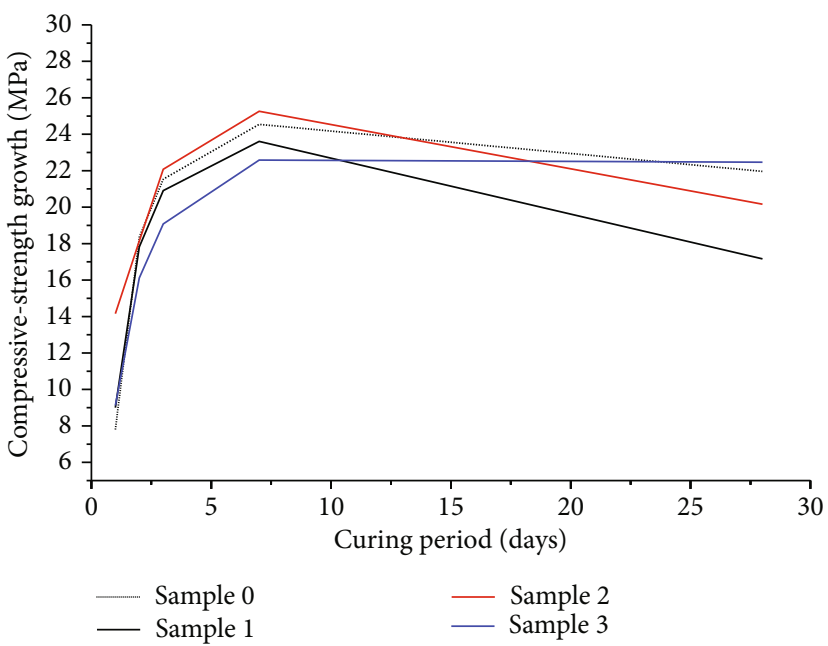

Figure 9: Compressive-strength test 2. Note: sample 0: pure cement (no additive added); sample 1: FLA A added (FLA A and SXY 0.25\%BWOC); sample 2: PVAGB/FLA A added (PVAGB $0.20 \%$ BWOC, FLA A, and SXY 0.25\%BWOC); sample 3: PVAGB/FLA A added (PVAGB 0.15\%BWOC, FLA A, and SXY $0.25 \% \mathrm{BWOC)}$.

\subsection{Effect of PVAGB Polymer Additive to Cement- Based Material}

3.3.1. Compressive-Strength Test. For comparison of the PVAGB effect to material mechanical strength after FLA 


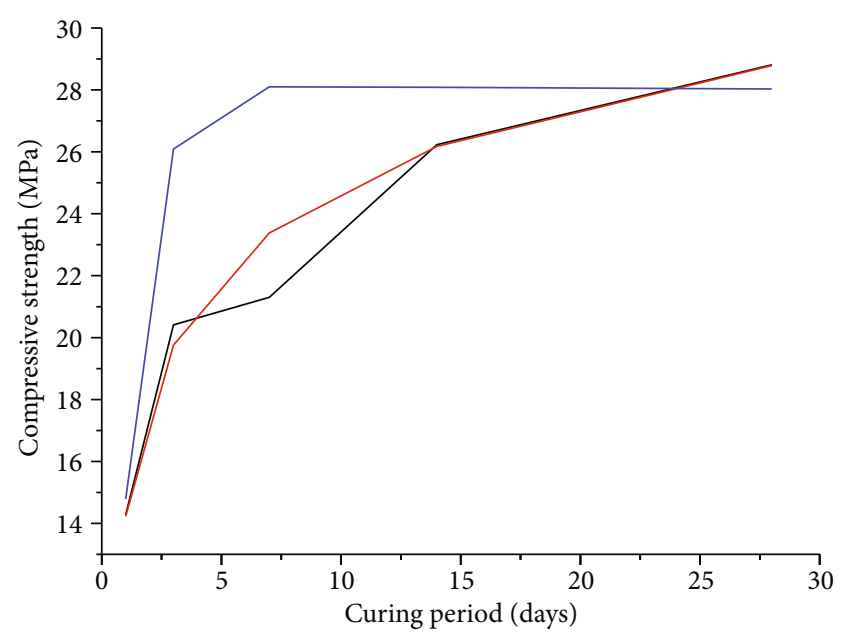

- Sample 1\#

- Sample 2\#

- Sample 3\#

Figure 10: Compressive-strength test 3. Note: sample 1\#: FLA A added (FLA A 0.5\%BWOC, SXY 0.75\%BWOC); sample 2\#: FLA A added (FLA A 0.7\%BWOC, SXY 0.75\%BWOC); sample 3\#: PVAGB/FLA A added (PVAGB 0.20\%BWOC, FLA A 0.5\%BWOC, and SXY 0.75\%BWOC).

A addition, a content control experiment was carried out as shown in Figures 8 and 9, and due to the possible negative effect of SXY-2 to the material when FLA A is added, the content was controlled at $0.25 \% \mathrm{BWOC}$ and FLA addition controlled at $0.25 \% \mathrm{BWOC}$. But the result was a success, with $0.15 \%$ BWOC PVAGB addition, combined with $0.25 \%$ BWOC FLA A, the cement-based material showed no obvious strength retrogression compared with the pure cement-based material. This means the use of lower content combined with proper content of PVAGB was beneficial to the stable mechanical strength of the cement-based material. In the meantime, the test carried out as in Figure 8 was also a controlled experiment set for the experiment shown in Figure 9.

As depicted in Figure 9, there was no doubt that the new formula, $0.2 \%$ BWOC PVAGB and 0.5\%BWOC FLA A together with $0.75 \% \mathrm{BWOC}$ SXY-2, was beneficial for mechanical strength development. When content of FLA A, PVAGB, and SXY -2 increased to $0.2 \%$ BWOC, $0.5 \%$ BWOC, and $0.75 \% \mathrm{BWOC}$, respectively, the compressive strength of test samples increased from $22 \mathrm{MPa}$ to over $28 \mathrm{MPa}$. Due to the hindering effect of FLA A to the hydration process of the cement-based material (Figure 8), the acceleration function to the early hydration process was possibly caused by PVAGB, which caused the formation of more $\mathrm{C}-\mathrm{S}-\mathrm{H}$ gels at the early period (Figures 7 and 8). Though the cement-based material showed a minor value at 7-day curing with $0.15 \%$ BWOC PVAGB, the 7 -day curing compressive strength was increased to $28 \mathrm{MPa}$ with $0.20 \% \mathrm{BWOC}$ PVAGB.

Specifically, as shown in Figure 9, there was a compressive-strength value decrease phenomenon for 0.10 or $0.15 \%$ BWOC PVAGB addition with FLA A with a fixed adding proportion $(0.25 \% \mathrm{BWOC})$. And the formula of
TABle 6: Fluid loss test (PVAGB and FLA A compound additives).

\begin{tabular}{lcccc}
\hline Test no. & $\begin{array}{c}\text { PVAGB } \\
(\% \text { BWOC) }\end{array}$ & $\begin{array}{c}\text { FLA A } \\
(\% B W O C)\end{array}$ & $\begin{array}{c}\text { SXY-2 } \\
(\% B W O C)\end{array}$ & $\begin{array}{c}\text { Fluid loss }(\mathrm{mL}) \\
(30 \mathrm{~min})\end{array}$ \\
\hline 1 & 0 & 3 & 0.75 & 110.2 \\
2 & 0.2 & 0.5 & 0.75 & 108 \\
3 & 0.2 & 0.75 & 0.75 & 66 \\
\hline
\end{tabular}

Note: test condition as $80^{\circ} \mathrm{C}\left(176^{\circ} \mathrm{F}\right), 6.9 \mathrm{MPa}$, and fluid loss in 30 minutes.

0.15\%BWOC PVAGB and 0.25\%BWOC FLA A showed stable compressive-strength development of more than $22 \mathrm{MPa}$. So, combined with fluid loss test results (Table 4), it was estimated that PVAGB and FLA A should be in a proper ratio to keep stability of application functions in both compressivestrength stability and cement fluid loss control ability.

Also, as displayed in Figures 9 and 10, the PVAGB polymer was still a proper choice regarding the stable increase of compressive-strength performance of the cement-based material. And the 0.2\%BWOC PVAGB and $0.5 \% \mathrm{BWOC}$ FLA A compound formula got an early-developed compressive strength at the 7-day curing period compared to 0.5 or 0.7\%BWOC FLA A, which showed stable 7-day to 28-day compressive strength for over $28 \mathrm{MPa}$.

So, cross-linked polyvinyl acetal adhesive-PVAGB showed an excellent benefit to the early stability of mechanical properties when coordinated with proper proportion of FLA A, i.e., $0.25 \%$ BWOC FLA A coordinated with $0.15 \%$ BWOC PVAGB, or $0.5 \%$ BWOC FLA A coordinated with $0.2 \% B W O C$ PVAGB. So, higher proportion addition of PVAGB and FLA A, with proper addition ratio, was a potential excellent fluid loss additive formula, which exerts a dual-function benefit in both excellent compressivestrength performance and superior fluid loss control ability. Besides, as shown in Figure 9, 28 MPa was not the biggest compressive-strength value for the cement-based material, but it was predicted that the use of PVAGB could be the early hydration accelerator and keep the mechanical stability of $28 \mathrm{MPa}$ in a 28 -day observation period.

However, as Zhang et al. depicted [45], the class G Portland cement could be with nearly perfect hydration of about $110^{\circ} \mathrm{C}$ with stable compressive-strength development of nearly $30 \mathrm{MPa}$. Thus, PVAGB and FLA A were utilized as the fluid loss additive, but there was no doubt that the dual use of proper content of PVAGB and FLA A was useful to reasonably control the mechanical performance of the cement-based material. So, in our research, suitable fluid loss additive, i.e., 0.2\%BWOC PVAGB, 0.5\%BWOC FLA A, and 0.75\%BWOC SXY-2, was with a relatively perfect early hydration process.

3.3.2. Fluid Loss Test $\left(80^{\circ} \mathrm{C}\right)$. According to Table 6, $0.75 \%$ BWOC SXY-2 was used, and fluid loss volume was decreased to below $100 \mathrm{~mL}$ with only $0.20 \%$ BWOC PVAGB and $0.5 \%$ BWOC FLA A additive. And other combined contents of PVAGB and FLA A also showed excellent fluid loss control ability. And PVAGB and FLA A showed a coordination effect in respect of fluid loss control ability. When FLA A content just increased from $0.5 \% \mathrm{BWOC}$ to $0.75 \% \mathrm{BWOC}$, the fluid loss volume showed a big decrease of over $40 \mathrm{~mL}$. At 


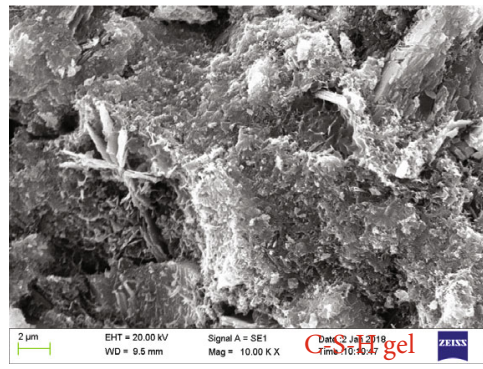

(a)

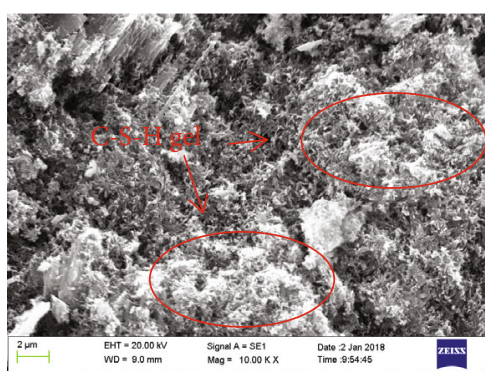

(c)

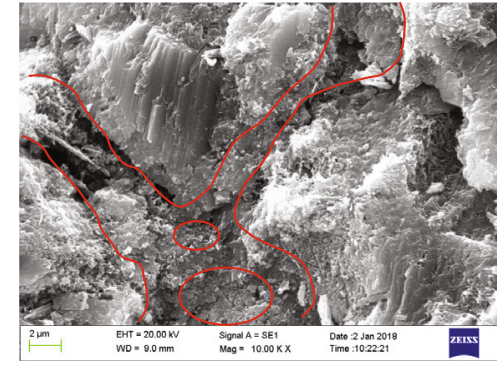

(b)

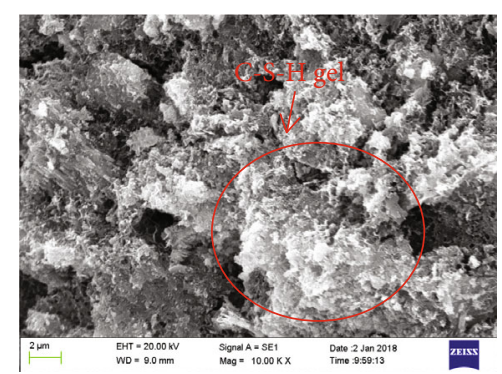

(d)

FIgURE 11: SEM images of hydrating cement-based material with different formulas. FLA A (0.7\%BWOC) added (a, b); PVAGB/FLA A $(0.2 / 0.5 \%$ BWOC) added $(c, d)$. $(a, c)$ are section direction images; $(b, d)$ are axial direction images.

$80^{\circ} \mathrm{C}$, with $0.20 \%$ BWOC PVAGB and $0.5 \%$ BWOC FLA A used, the cement-based material could be with a fluid loss level same as that when $3 \%$ BWOC FLA A is used. With proper weight ratio of PVAGB to FLA A additive, the fluid loss volume could be further controlled.

\subsubsection{SEM Analysis for Microstructure of Cement-Based} Material. As shown in Figures 8 and 11, an axially incompatible gap defect was observed when the FLA A additive was added, which caused the formation of microlevel gaps within the cement-based material. It was wrongly distributed along the axial direction of the material. However, with PVAGB added, no gluing gap was observed. There was no doubt that the PVAGB additive was beneficial to the hydration process for better formation of the C-S-H gel phase.

Specifically, as depicted in Figure 11, for the added FLA A (0.7\%BWOC), axial direction of the material showed more microlevel pores and more gluing effect at the interface of the cement-based material, but little C-S-H gel aggregated product was formed when compared with the pure cementbased material (only 0.75\%BWOC SXY-2 added). Besides, a less hexagonal plate $\mathrm{Ca}(\mathrm{OH})_{2}$ product was formed. As depicted by the section direction microstructure, the gluing microlevel gap was formed, and thus, the leakage channel of free water was formed. This may be the direct cause of sharply increased abnormal fluid loss volume. Besides, with respect to the mechanical perfection of the crystalline material, formation of an incompatible interface within the cement-based material was not only a potential developing line-plane defect to the cement-based material but also the destruction of its mechanical perfection. Furthermore, due to the formation of an early hydration shell, the addition of the FLA A additive caused an extra layer to hinder the bursting of the early hydration shell, and cement clinker particles were blocked from contacting free water and further hydration reaction was terminated. The formation of the free water channel was another reason for affecting the general hydration process of the cement-based material [41]. Thus, the compressive-strength test showed that compressive strength increased when content increased from $0.5 \% \mathrm{BWOC}$ to $0.75 \% \mathrm{BWOC}$ and decreased from $0.75 \% \mathrm{BWOC}$ to $1.0 \% \mathrm{BWOC}$, and then an irregular decrease of $1 \sim 3 \%$ BWOC that compared to $0.75 \%$ BWOC was shown (Figures 5(1) and 6(2)).

Relatively, though the FLA A additive led to the negative effect of physicochemical properties of the cement-based material, more C-S-H gel was formed due to the added PVAGB. And the C-S-H gel was equally distributed and formed into a network in both the sectional direction and the axial direction. Furthermore, the material showed a denser physical structure. Besides, the promotion to hydration increased the adsorption sites of $\mathrm{Ca}^{2+}$ hydration products for FLA A chains. As a result, the more AMPS-based polymers were adsorbed simultaneously onto more area range of the hydration products rather than mostly aggregating on some part of cement-based material interfaces [46]. Therefore, PVAGB effectively improved the compatibility problem caused by the competitive adsorption of AMPS polymer chains to limited $\mathrm{Ca}^{2+}$ hydrating cement particles at the early hydration period.

Because FLA A showed stronger chemisorption behavior to $\mathrm{Ca}^{2+}$ or other high-valence-state metal ions $[1,5]$, an estimation was made that most FLA A chains were absorbed on the same part surface of the cement-based material rather than a spatial uniform distribution. But this estimation should be based on analysis of chemisorption behavior of FLA to $\mathrm{Ca}^{2+}$ before and after PVAGB is added. Thus, the ZETA potential analysis test was utilized. 
TABLE 7: Polymer solution ZETA potential tested results.

\begin{tabular}{lc}
\hline Polymer solution & ZETA potential value $(\mathrm{mV})$ \\
\hline Solution 1 & -26.4 \\
Solution 2 & 15.8 \\
Solution 3 & 93.6 \\
Solution 4 & 35.2 \\
Solution 5 & 347.1 \\
Solution 6 & -5.9 \\
Solution 7 & 43.7 \\
\hline
\end{tabular}

3.3.4. ZETA Potential Test (Polymer Solution). Previous research results depicted that adding a cationic group could cause reduction of the anionic charge of the AMPS additive $[5,34]$. As per the test results (Table 7 ), the FLA A additive showed strong absorption ability to $\mathrm{Ca}^{2+}$ and originally with a negative ZETA potential property, and PVAGB was designed to show a relatively positive ZETA potential and would impose the chemically absorbed behavior of AMPS units on FLA A chains. In fact, with PVAGB added, the ZETA potential deviation just decreased from $120 \mathrm{mV}$ to $43.7 \mathrm{mV}$. Above all, with the new fluid loss additive formula, excellent fluid loss control ability was shown (comparison by Tables 3-6).

So, better control ability to the $\mathrm{Ca}^{2+}$ positive ion due to assistance of FLA A and PVAGB addition was still reflected. This phenomenon may be contributed to the chelating and absorption properties of $\mathrm{SO}_{3}{ }^{-}$on AMPS unit, and each $\mathrm{Ca}^{2+}$ was possibly absorbed by two or more $\mathrm{SO}_{3}{ }^{-}\left(-\mathrm{SO}_{3} \mathrm{Na}\right)$ on AMPS units. As a result, FLA A chains were absorbed on the interface of the cement-based material. As competition occurred, the aggregating problem of FLA A chains was shown and wrong distribution of FLA A chains was formed. Then, some part of the material sample's interface was covered with much more aggregated FLA A chains, which resulted in the microlevel gaps within the cement-based material. In particular, most of these gaps were formed along its own axial direction.

Thus, a reason for the abnormal fluid loss volume was the disordered chemisorption behavior of AMPS units to $\mathrm{Ca}^{2+}$ hydrated cement particles [4]. The effectiveness decreased for a ZETA potential value of the FLA A solution which sharply increased from $-26.4 \mathrm{mV}$ to $93.6 \mathrm{mV}$. Thus, the whole multilayer filtration control system was not completely formed. And the fluid loss volume unexpectedly increased. However, with the cationic PVA, even with $0.6 \mathrm{~g} / \mathrm{L} \mathrm{Ca}^{2+}$ added, the FLA A solution just increased from $-26.4 \mathrm{mV}$ to $43.7 \mathrm{mV}$, in which a deviation value that reached to $18.6 \mathrm{mV}$ was caused by addition of PVAGB.

Besides, addition of PVAGB caused a positive ZETA potential deviation to the FLA A solution, which was contrary to a normal ZETA potential decrease of adding PVA [47]. Thus, PVAGB showed a positive ZETA potential. Within PVAGB chains, the cross-linking technique just got the decrease of negative ions, i.e., hydroxyl groups. So, glyoxal was the key factor for the potential change. So, glyoxal-modified hydroxyl groups were formed as numerous positive chemical groups.
3.4. Function Synergy Mechanism. As depicted by fluid loss test results, compression-strength test results, FTIR analysis results, and SEM analysis results, both FLA A and PVAGB additives contributed to a much less fluid loss volume. Besides, single use of the FLA A additive showed obvious physicochemical damage to the properties of the cementbased material, as shown in Figure 12(a).

Depicted as FTIR analysis, SEM analysis, and ZETA potential test results, the function synergy of FLA A and PVAGB was a fact and could contribute to the better fluid loss control ability and better mechanical performance. As the ZETA potential test result described, the FLA A additive showed better absorption behavior to PVAGB polymer chains; thus, numerous absorption points between FLA A chains and PVAGB chains were formed (Figure 12(b)). And a stable network of the PVAGB polymer was formed into a spatial and structural support to FLA A, which imposed a better dispersion of FLA A chains and was less absorbed on the material interface due to the fixed, cationic, and cross-linked network of the PVAGB polymer (Figures 1 and 12(b)). Thus, FLA A were reasonably absorbed on cement particles. And the complete filtration layer was formed rather than aggregated and glued on the interface, which caused incompatible cementing interfaces and formation of free water flowing gaps within the cement-based material (Figures 11(a) and 11(b)). So, a renewed and completed fluid loss control system was formed. Besides, due to the adjustment function of PVAGB to FLA A chains, plus the hydrophilic properties of PVAGB itself, the cementbased material showed better and more excellent hydration process. Besides, the new additive system showed much better chemisorption ability to $\mathrm{Ca}^{2+}$, as shown in Table 7 . And the reason for the rearrangement behavior of FLA A chains was the competitive chemisorption behavior of $\mathrm{SO}^{3-}$ to cationic points on the PVA polymer additive and absorbed behavior of $\mathrm{SO}^{3-}$ to $\mathrm{Ca}^{2+}$ hydrating cement particles, and thus, the chelating effect of AMPS-Na units to $\mathrm{Ca}^{2+}$ hydrating cement particles was much weaker but with better absorbed behavior to more $\mathrm{Ca}^{2+}$ hydrating cement particles. So, FLA A chains were uniformly distributed and imposed the perfection of fluid loss control multilayers. Beside, when mixing PVAGB to the FLA A solution, the absorption behavior of $\mathrm{SO}_{3}{ }^{-}$to glyoxal-modified hydroxyl groups could get a dual effect, both the absorption force of $\mathrm{SO}_{3}{ }^{-}$and possible adhesion force of glyoxal-modified hydroxyl groups [19-21].

\section{Conclusions}

(1) The modification to PVA is a success. PVAGB is a new kind of cationic PVA polymer for its glyoxalmodified hydroxyl groups, which shows the cationic ion properties. And it makes the chemisorption behavior of the FLA A additive to PVAGB chains become a possibility. PVAGB showed excellent absorbed property by the FLA A additive. The compound additive formula PVAGB/FLA A fluid loss control system has a superior and more stable fluid loss control ability, i.e., less than $50 \mathrm{~mL}$ at $30^{\circ} \mathrm{C}$ and 


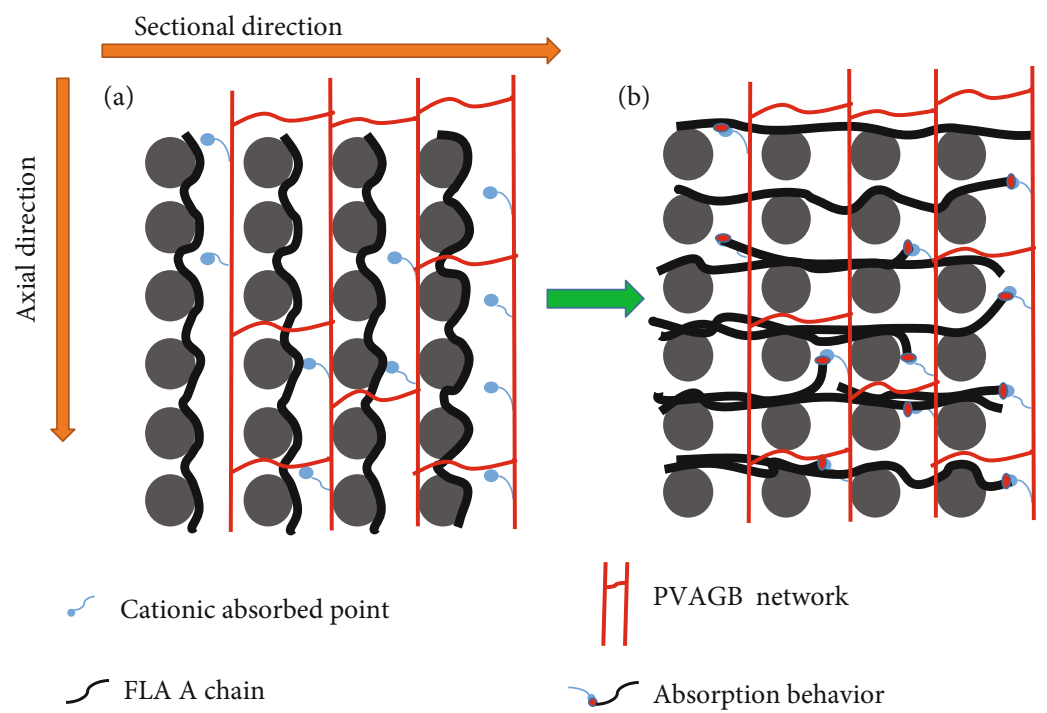

FIGURE 12: Formation of excellent fluid loss control system.

$108 \mathrm{~mL}$ at $80^{\circ} \mathrm{C}$ with $0.2 \%$ BWOC PVAGB and $0.50 \%$ BWOC FLA A addition

(2) FLA A additive, a kind of AMPS-type fluid loss additive, showed a much stronger chelating ability to $\mathrm{Ca}^{2+}$ and thus caused a wrong chemically absorbed behavior to $\mathrm{Ca}^{2+}$ hydrated cement particles. Then, fluid loss control ability was sharply increased and other defects of the cement-based material occurred. Furthermore, material samples showed a worse hydration speed due to FLA A added in the cementbased material. The reason for it should be the hindering effect to early hydration, for which the cement clinker could not contact with free water to accelerate the secondary hydration of the cement-based material. Besides, as the fluid loss volume increased, the free water kept within the hydrating structure became less, which is of no benefit to hydration of the cement-based material

(3) Acetone-formaldehyde-sulfonate dispersant SXY-2 showed an accelerating effect to the formation of hexagonal plate form $\mathrm{Ca}(\mathrm{OH})_{2}$, and more sulfate ions were formed. However, it showed little contribution to the formation of the C-S-H gel, which was the main reason for reinforcement of compressivestrength performance after PVAGB additive addition

(4) PVAGB, a fixed and dispersing support to the FLA A additive for its cationic properties and hydrophilic properties, showed acceleration effect to the hydration process of the cement-based material. Besides, for associating with the FLA additive and SXY-2, the cement-based material showed better compressive performance of $28 \mathrm{MPa}$. All this due to the accelerating formed C-S-H gel network. And the adhesion properties of PVAGB on the interfaces may be also beneficial in respect of reinforcement of compressive-strength performance. Furthermore, due to the accelerating effect of PVAGB on the hydration process of the cement-based material, PVAGB effectively improved the compatibility problem caused by the competitive adsorption between AMPS polymer chains to the limited number of $\mathrm{Ca}^{2+}$ hydrating cement particles at the early hydration period

(5) The new fluid loss additive formula, i.e., 0.2\%BWOC PVAGB, 0.5\%BWOC FLA A, and 0.75\%BWOC SXY-2, not only exerted excellent fluid loss control ability but also accelerated the formation of the relatively perfect early hydration process for the cementbased material

\section{Data Availability}

All data generated or analysed used to support the findings of this study are included within the article "Function Synergy of Cross-Linked Cationic PVA Polymer to AMPS-Type Fluid Loss Additive Used for Cement-Based Material." And its extra relating supplementary information files are openly available at https://figshare.com/s/074f0d31a6d77a8856b. So researchers can obtain all the data to verify the results, replicate the analysis, and conduct secondary analyses by reading my manuscript.

\section{Conflicts of Interest}

Authors disclose all relationships or interests that could have direct or potential influence or impart bias on the work in a summary statement. There is no existing conflict; all authors declare that we have no conflict of interest.

\section{Authors' Contributions}

All authors have agreed to submit this final manuscript. 


\section{Acknowledgments}

This study was supported and funded by the National Natural Science Foundation of China (grant number 51874254); the authors are thankful for their financial support. And the authors also want to thank the Advanced Cementing Materials Research Center of SWPU, for the kind assistance during laboratory testing and data analysis.

\section{References}

[1] A. M. Atta, S. A. Sayed, A. B. Farag, H. S. Ismail, Z. M. Mohamed, and A. M. Eraky, "Application of crosslinked Acrylamidoxime/2-Acrylamido-2-methylpropane sulfonic acid copolymer in wastewater treatment," Journal of Dispersion Science and Technology, vol. 32, no. 9, pp. 1285-1295, 2011.

[2] G. S. Chauhan, S. Chauhan, U. Sen, and D. Garg, "Synthesis and characterization of acrylamide and 2-hydroxyethyl methacrylate hydrogels for use in metal ion uptake studies," Desalination, vol. 243, no. 1-3, pp. 95-108, 2009.

[3] A. I. Nechaev, I. I. Lebedeva, V. A. Val'tsifer, and V. N. Strel'nikov, "Influence of the composition of acrylamide-acrylonitrile2-acrylamido-2-methylpropanesulfonic acid terpolymer on its resistance to high temperatures and salts," Russian Journal of Applied Chemistry, vol. 89, no. 8, pp. 1296-1301, 2016.

[4] D. Chen, J. Guo, Y. Xu et al., "Adsorption behavior and mechanism of a copolymer used as fluid loss additive in oil well cement," Construction and Building Materials, vol. 198, pp. 650-661, 2019.

[5] J. Plank, A. Brandl, and N. R. Lummer, "Effect of different anchor groups on adsorption behavior and effectiveness of poly(N,N-dimethylacrylamide-co-Ca 2-acrylamido-2-methylpropanesulfonate) as cement fluid loss additive in presence of acetone-formaldehyde-sulfite dispersant," Journal of Applied Polymer Science, vol. 106, no. 6, pp. 3889-3894, 2007.

[6] A. S. Al-Yami, "An overview of different chemicals used in designing cement slurries for oil and gas wells," SPE Kuwait Oil and Gas Show and Conference, vol. 175259, 2015.

[7] F. T. G. Dias, R. R. Souza, and E. F. Lucas, "Influence of modified starches composition on their performance as fluid loss additives in invert-emulsion drilling fluids," Fuel, vol. 140, pp. 711-716, 2015.

[8] H. Han and J. Zhang, "Lightly branched poly(vinyl alcohol) for fluid loss additive," Journal of Applied Polymer Science, vol. 130, pp. 4608-4612, 2013.

[9] W. Cui, G. Jiang, and Y. He, "New structure found in a filter cake with the addition of an amphoteric polymer fluid loss additive," Journal of Applied Polymer Science, vol. 136, no. 38, p. 47965, 2019.

[10] O. T. Salami and J. Plank, "Influence of electrolytes on the performance of a graft copolymer used as fluid loss additive in oil well cement," Journal of Petroleum Science and Engineering, vol. 143, pp. 86-94, 2016.

[11] S. Guo, Y. Lu, Y. Bu, and B. Li, "Effect of carboxylic group on the compatibility with retarder and the retarding side effect of the fluid loss control additive used in oil well cement," Royal Society Open Science, vol. 5, no. 9, p. 180490, 2018.

[12] F. Liu, G. Jiang, S. Peng, Y. He, and J. Wang, "Amphoteric polymer as an anti-calcium contamination fluid-loss additive in water-based drilling fluids," Energy \& Fuels, vol. 30, no. 9, pp. 7221-7228, 2016.
[13] F.-J. Ulm and S. James, "The scratch test for strength and fracture toughness determination of oil well cements cured at high temperature and pressure," Cement and Concrete Research, vol. 41, no. 9, pp. 942-946, 2011.

[14] P. J. M. Monteiro and W. P. Andrade, "Analysis of the rockcement paste bond using probabilistic treatment of brittle strength," Cement and Concrete Research, vol. 17, no. 6, pp. 919-926, 1987.

[15] N. Bestaoui-Spurr, A. M. Gomaa, H. G. Hudson, D. V. S. Gupta, S. G. Nelson, and H. D. Brannon, "Method of enhancing fracture complexity using far-field divert systems," 2017.

[16] J. Plank, N. R. Lummer, F. Dugonjic-Bilic, and D. Sadasivan, "Comparative study of the working mechanisms of different cement fluid loss polymers," SPE International Symposium on Oilfield Chemistry, no. article 121542-MS, 2009.

[17] H. A. Hussein, A. R. Ismail, S. I. Amran, and A. M. Arshad, "Feasibility study of kenaf as fluid loss additive in waterbased mud," IOP Conference Series: Materials Science and Engineering, vol. 458, article 012027, 2018.

[18] J. Yu and D. Stephan, "Hydration kinetics of Portland cement in the presence of vinyl acetate ethylene latex stabilized with polyvinyl alcohol," Journal of Materials Science, vol. 53, no. 10, pp. 7417-7430, 2018.

[19] H. Wang, "Study on a new type modified poly(vinyl alcohol)," China Adhesives, vol. 25, no. 7, p. 57, 2016.

[20] H. Toutanji, B. Xu, and J. Gilbert, "Impact resistance of poly (vinyl alcohol) fiber reinforced high-performance organic aggregate cementitious material," Cement and Concrete Research, vol. 40, no. 2, pp. 347-351, 2010.

[21] Y. Zhang, P. C. Zhu, and D. Edgren, "Crosslinking reaction of poly(vinyl alcohol) with glyoxal," Journal of Polymer Research, vol. 17, no. 5, pp. 725-730, 2010.

[22] Y. Li, W. Li, D. Deng, K. Wang, and W. H. Duan, "Reinforcement effects of polyvinyl alcohol and polypropylene fibers on flexural behaviors of sulfoaluminate cement matrices," Cement and Concrete Composites, vol. 88, pp. 139-149, 2018.

[23] W. Zhao, Q. Zhang, and J. Guan, "Model of coherent interface formation in cement-based composites containing polyblend of polyvinyl alcohol and methylcellulose," Journal of Wuhan University of Technology-Materials Science Edition, vol. 17, no. 2, pp. 58-61, 2002.

[24] B. Arisoy and H. C. Wu, "Material characteristics of high performance lightweight concrete reinforced with PVA," Construction and Building Materials, vol. 22, no. 4, pp. 635-645, 2008.

[25] S. Zhang, H. Teng, and S. Teng, "Instant hydroxypropyl methyl cellulose ether and its preparation method," Patent, CHINA, CN101830990A, 2010.

[26] H. Frank and B. Jorn, "Process for the preparation of hydrocolloid mixtures having improved dispersibility," Patent, US, US5062889, 1991.

[27] Z. Yang, D. Jiang, and G. Xiaojing, "Experimental study on mechanics performance of polyvinyl alcohol fiber reinforced cement-based composites," Applied Mechanics and Materials, vol. 584-586, pp. 1477-1481, 2014.

[28] B. Gupta, S. Anjum, and S. Ikram, "Physicochemical studies of crosslinked thiolated polyvinyl alcohol hydrogels," Polymer Bulletin, vol. 70, no. 8, pp. 2437-2450, 2013.

[29] Testing of well cements, 2012.

[30] Recommended practice for testing well cements, 2013.

[31] H. Ding, M. Wang, M. Li et al., "Synthesis of a water-soluble, rubber seed oil-based sulfonate and its tribological properties 
as a water-based lubricant additive," Journal of Applied Polymer Science, vol. 135, no. 15, p. 46119, 2018.

[32] H. T. Bæk, Physical and Thermodynamical Properties of Water Phases in Hardening Cement Paste [D], Aalborg University, 2001.

[33] A. G. Nasibulin, S. D. Shandakov, L. I. Nasibulina et al., "A novel cement-based hybrid material," New Journal of Physics, vol. 11, no. 2, article 023013, 2009.

[34] J. Plank, N. R. Lummer, and F. Dugonjić-Bilić, "Competitive adsorption between an AMPS $^{\circledR}$-based fluid loss polymer and Welan gum biopolymer in oil well cement," Journal of Applied Polymer Science, vol. 116, no. 5, pp. NA-2919, 2010.

[35] P. A. N. Zuren, "Polymer chemistry (5th edition)," Chemical industry press(China), vol. 9, pp. 232-233, 2011.

[36] S. S. T. Moradi, N. I. Nikolaev, and Y. Naseri, "Developing high resistant cement systems for high-pressure, high temperature applications," in SPE Russian Petroleum Technology Conference, Moscow, Russia, October 2015.

[37] E. G. Ballweber, R. H. Jansma, and K. G. Phillips, "Paper fiber additive containing polyacrylamide blended with glyoxal and polymeric diallyldimethyl ammonium chloride as a cationic regulator," Patent, US, US04217425, 1980.

[38] S. Demirdag, "The effect of using different polymer and cement based materials in pore filling applications on technical parameters of travertine stone," Construction and Building Materials, vol. 23, no. 1, pp. 522-530, 2009.

[39] Y. Tan, M. Gu, W. Li, and L. Guo, "Effect of a filled adhesive as the desensitizer on bond strength of "Self-Adhesive Cements To" differently severity of fluorosed dentin," Microscopy Research and Technique, vol. 81, no. 8, pp. 805-815, 2018.

[40] D. Bülichen and J. Plank, "Role of colloidal polymer associates for the effectiveness of hydroxyethyl cellulose as a fluid loss control additive in oil well cement," Journal of Applied Polymer Science, vol. 126, no. S1, pp. E25-E34, 2012.

[41] G. M. M. Bell, J. Bensted, F. P. Glasser, E. E. Lachowski, D. R. Roberts, and S. A. Rodger, "Instrumental investigations of hydration of class J oilwell cement," Advances in Cement Research, vol. 5, no. 18, pp. 71-79, 1993.

[42] L. Karen, H. Chris, J. Tim, B. Paul, T. Xavier, and L. Andrew, "New techniques for monitoring cement hydration under simulated well conditions," in Proceedings of the International Symposium on Oilfield Chemistry, San Antonio, Texas (USA), February 1995.

[43] J. S. Lots, The hydration of class G oilwell cement, The University of London and Imperial College (UK), 1993.

[44] W. Franus, R. Panek, and M. Wdowin, "SEM investigation of microstructures in hydration products of Portland cement," 2nd International Multidisciplinary Microscopy and Microanalysis Congress, vol. 164, pp. 105-112, 2015.

[45] J. Zhang, M. Xu, L. Gao, and H. Xiao, "Effect of temperature and additives on strength of class G oilwell cement," Oil Drilling \& Production Technology (CHINA), vol. 3, no. 82, pp. 19-23, 2003.
[46] L. Cao, J. Guo, J. Tian et al., "The ability of sodium metasilicate pentahydrate to adjust the compatibility between synthetic fluid loss additives and retarders applying in oil well cement," Construction and Building Materials, vol. 158, pp. 835-846, 2018.

[47] H. Shagholani, S. M. Ghoreishi, and M. Mousazadeh, "Improvement of interaction between PVA and chitosan via magnetite nanoparticles for drug delivery application," International Journal of Biological Macromolecules, vol. 78, pp. 130-136, 2015. 